\title{
Using HEC-FIA to identify Indirect Economic Losses
}

\author{
William Lehman $^{1, a}$, Dr. Miles Light ${ }^{2}$ \\ 1 USACE, 209 Second St, Davis CA, 95691, United States of America \\ 2 Business Research Division University of Colorado Boulder, 995 Regent Drive, 419 UCB, Boulder, CO 80309 , United States of \\ America
}

\begin{abstract}
The United States Army Corps of Engineers' Hydrologic Engineering Center developed the HEC-FIA (Flood Impact Analysis) software to assist in the estimation of consequences with uncertainty. By estimating the consequences, the benefits of existing and future flood risk management measures can be evaluated and compared.

HEC-FIA utilizes geospatial datasets to help users build structure inventories and assign values and population per structure. Using this information and geospatially derived flood depth grids (provided by most hydraulic models), HEC-FIA estimates direct economic, indirect economic, agricultural, and life loss consequences for flood hazards. HEC-FIA can compute results for a single event in either deterministic mode or in uncertainty mode which utilizes a Monte Carlo approach. The user can define the uncertainties about any structure in the floodplain in many ways, and each has various impacts on the different consequence calculations. For example, foundation heights, structure values, and depth-damage relationships impact economic consequences, while foundation heights, warning issuance times, and fatality rates impact the life loss calculations. All of these parameters can be defined with uncertainty. HEC-FIA can also be linked into HEC-WAT (Watershed Analysis Tool) with the FRA (Flood Risk Analysis) compute option to randomize the hydraulic events being evaluated in HEC-FIA so that hydrologic, hydraulic, geotechnical, and economic uncertainties can all be represented and evaluated by alternative within the floodplain.

This paper will describe how HEC-FIA can be utilized to help evaluate the indirect economic consequences for various alternatives within a floodplain. The computational methods for indirect economic losses utilize a Computable General Equilibrium model to describe the secondary and tertiary impacts of loss of service, loss of laborers, and reductions in demand for intermediary goods.
\end{abstract}

\section{Introduction}

The purpose of this paper is to illustrate the capabilities of the software program HEC-FIA, and provide some insight into how the program is used to evaluate the consequences from various flood events. In this paper, consequences are separated into two categories, direct and indirect consequences. The definition of direct and indirect follows recently-developed guidelines for the estimation of economic impacts of dam spillage, published by the (Department of Homeland Security) DHS. Under these guidelines, the cost of damaged buildings, their contents, bridges, and loss of life are considered to be direct economic impacts. The subsequent reduction to business income and employment are called indirect economic impacts.

HEC-FIA is a single event model in that it evaluates the consequences of one hydraulic event at a time. A hydraulic event is composed of four hydraulic characteristics (See Figure 1):

1. Depth

2. Depth times Velocity

3. Arrival time of a critical threshold.

4. Duration above a critical threshold.

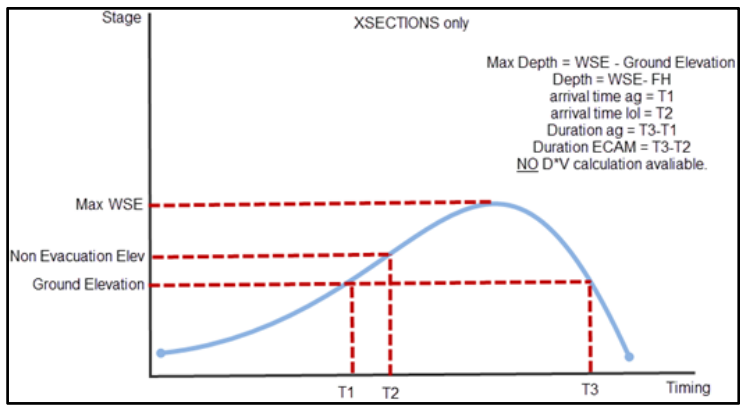

Figure 1 How Hydraulic parameters are calculated in HEC-FIA

These parameters are used in the evaluation of damages at each damageable element. The remainder of this document will explain how these hydraulic characteristics impact direct, and indirect consequence calculations.

\section{HEC-FIA calculations \\ Direct \\ damage}

HEC-FIA represents structures using a point shape file. This means each structure is defined with an $\mathrm{x} y$ location and a series of attributes which describe the structure. Using a point shape file allows the direct damage computation to be evaluated and stored at each individual structure. The geospatial nature of

\footnotetext{
${ }^{\text {a }}$ Corresponding author: William.p.lehman@usace.army.mil
} 
structures also lends itself to faster development and review of structure inventories.

\section{$\underline{\text { Direct Dollar Damages }}$}

HEC-FIA calculates the direct losses for structures in the form of structure damage, content damage, and vehicle damage in accordance with USACE policy. These damages are calculated in the traditional methods as described in ER 1105-2-100 (USACE, 2000) using relationships such as those described in EGM 01-03 (EGM, 2003) (see Figure 2). As you can see in the table, there are defined Standard Deviations of Damage for each incremental ordinate.

Structure Depth-Damage

\begin{tabular}{|r|r|r|}
\hline \multicolumn{3}{|c|}{ One Story, No Basement } \\
\hline Depth & Mean of Damage & $\begin{array}{c}\text { Standard Deviation } \\
\text { of Damage }\end{array}$ \\
\hline-2 & $0 \%$ & $0.0 \%$ \\
\hline 1 & $2.5 \%$ & $2.7 \%$ \\
\hline 0 & $13.4 \%$ & $2.0 \%$ \\
\hline 1 & $23.3 \%$ & $1.6 \%$ \\
\hline 2 & $32.1 \%$ & $1.6 \%$ \\
\hline 3 & $40.1 \%$ & $1.8 \%$ \\
\hline 4 & $47.1 \%$ & $1.9 \%$ \\
\hline 5 & $53.2 \%$ & $2.0 \%$ \\
\hline 6 & $58.6 \%$ & $2.1 \%$ \\
\hline 7 & $63.2 \%$ & $2.2 \%$ \\
\hline 8 & $67.2 \%$ & $2.3 \%$ \\
\hline 9 & $70.5 \%$ & $2.4 \%$ \\
\hline 10 & $73.2 \%$ & $2.7 \%$ \\
\hline 11 & $75.4 \%$ & $3.0 \%$ \\
\hline 12 & $77.2 \%$ & $3.3 \%$ \\
\hline 13 & $78.5 \%$ & $3.7 \%$ \\
\hline 14 & $79.5 \%$ & $4.1 \%$ \\
\hline 15 & $80.2 \%$ & $4.5 \%$ \\
\hline 16 & $80.7 \%$ & $4.9 \%$ \\
\hline
\end{tabular}

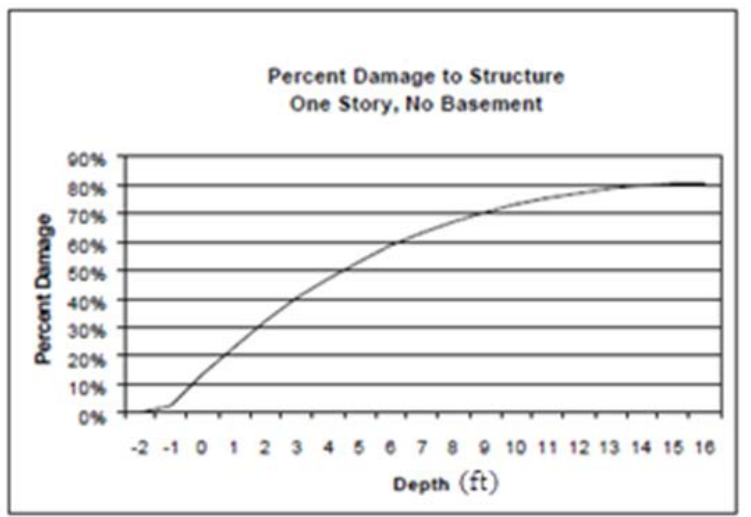

Figure 2. Depth Damage Relationship for One Story No Basement from EGM 01-03

It is important to note the impact of uncertainty in the evaluation of direct economic losses. HEC-FIA allows the user to define uncertainty in depth damage relationships, structure values, and structure value to content ratios. Each of these uncertainties will be sampled when calculating the direct losses for a given flood event. Each direct loss calculation would produce different capital loss ratios (defined in 4.4), which in turn would create a different output from the indirect economic loss modeling.

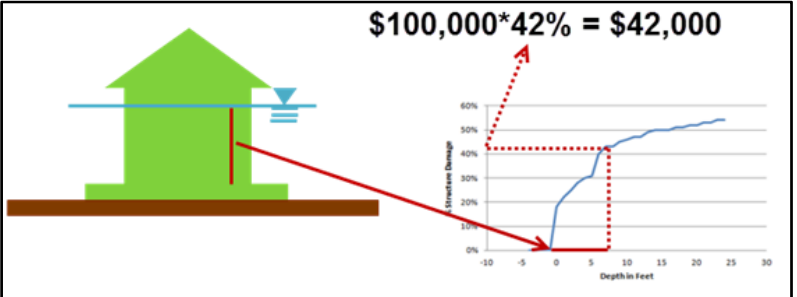

Figure 3. Using a Depth Percent Damage Relationship to calculate Damage

In HEC-FIA depth damage relationships are stored at occupancy types which describe the susceptibility of a structure to be damaged by an event. Each structure is assigned an occupancy type in the structure shape file attributes by the user. Each occupancy type contains a depth percent damage relationship, and each structure contains a structure value description. Using the general process defined in Figure 3 HEC-FIA computes damage at each structure. Since structures store many attributes in their database, the user can organize direct damage estimates in many ways, such as by Occupancy Type. Each occupancy type is grouped into a larger category called damage categories. Damage categories map very broadly to sectors of the economy. Examples of damage categories would be:
1. Residential
2. Industrial
3. Commercial
4. Public

Examples of occupancy types under the industrial damage category would be:
1. Heavy Industrial
2. Light Industrial
3. ...

The occupancy type names and damage functions are user inputs, and could be modified to fit any user needs.

The output of a computation of direct dollar losses would be a shape file representing all of the damaged structures, with attributes describing maximum depth, dollar damages to structures, contents, and vehicles.

\section{Life Loss Computation}

Additionally, HEC-FIA calculates the loss of life from flooding events. While there are other human impacts, such as injuries or duress caused by the flooding, these are currently not evaluated by HEC-FIA. HEC-FIA uses a simplified approach of the LifeSim methodology defined by Dr. Bowles and Dr. McClelland, for more detail on the methodology refer to McClelland and Bowles 2002. The computational procedure for life loss consists of three main steps.

1. Initial Distribution of Population

2. Redistribution of Population 

a. Warning Issuance
b. Warning Diffusion
c. Protective Action Initiation
d. Evacuation

3. Shelter provided by final destination

Step two divides the population into three categories, not mobilized, mobilized and reached safety, or mobilized and were caught by the flood.

If warnings are given to the public sufficiently in advance of the flood, it is more likely that more individuals will reach safety in time. The quality of the warning message will impact the rate and participation in the evacuation process.

All individuals who were mobilized and caught by the flood have a very high fatality rate applied to them. Those who mobilized and reached safety are unharmed.

And finally those who were unable to mobilize or unwilling to mobilize in time are subject to fatality rates based on the shelter of the structures they remained in. There are two main criteria for evaluating the shelter provided by the final destination.

1. Stability Criteria

2. Submergence Criteria

Stability criteria is based on the construction type of the structure. This is defined by the occupancy type. Structures can be sorted into some basic categories such as:

\section{Wood Frame \\ 2. Concrete Block \\ 3. Masonry \\ 4. Steel}

Additionally the structures can be attached to a foundation or not. Depending on the construction of the building different depth times velocity and velocity thresholds can result in different stability criteria for the structures. More severe flood characteristics with less stable construction practices will yield higher fatality rates.

In addition to the Stability criteria, submergence criteria is utilized to evaluate fatality rates. The depth of the flood water relative to the height of the structure can impact the shelter provided by a structure. Additionally, characteristics of the individuals may impact their ability to vertically evacuate.

To evaluate submergence criteria, structures are given three lethality zones (See Figure 4):

1. Safe zone

2. Compromised Zone

3. Chance Zone

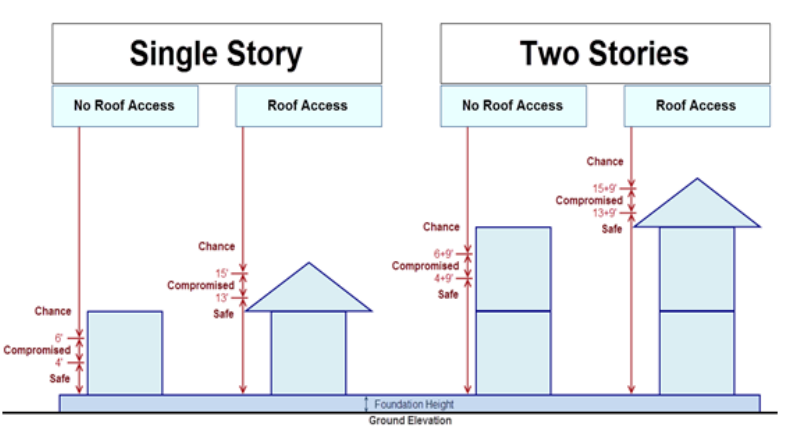

Figure 4 Lethality zones based on Structure Submergence criteria

The zones are determined based on a general rule:

A) For structures with no roof access the safe zone is from 0 to 4 feet above the start of the highest floor. The compromised zone is from 4 to 6 feet above the highest floor, and the chance zone is anything above 6 feet beyond the start of the highest floor.

B) For structures with roof access the safe zone is from 0 to 13 feet above the start of the highest floor. The compromised zone is from 13 to 15 feet above the highest floor, and the chance zone is anything above 15 feet beyond the start of the highest floor.

C) Additional floors (more than 1) will add 9 feet to all thresholds.

D) Population over the age of 65 will have no roof access even if the structure has roof access

The most severe lethality zone between submergence and stability criteria is used, and fatality rates are determined (see Figure 5). These are applied to the population that remains at the structure in question.

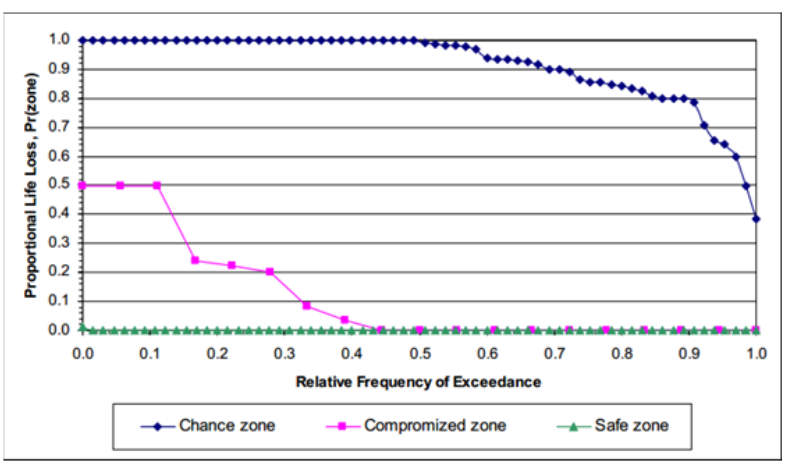

Figure 5 Fatality rates by Lethality category based on McClelland and Bowles 2002

Through this process HEC-FIA calculates those who evacuated, keeping track of how long they were evacuated, and how many people lost their lives. The resulting population displaced or harmed would be able to be aggregated by area, damage category, and occupancy type.

The resulting magnitude of the direct economic loss should be characterized as a function dependent upon 
the nature and timing of the event. Based on the above description of direct loss calculations, the magnitude of the loss of workers, buildings, and infrastructure estimated by the direct economic modeling will in fact be determined by the nature of the hazard through utilizing depth, duration, and depth times velocity. These damage driving parameters incorporate the nature and timing of the hydraulic event, and can be changed through the hydraulic model to represent structural alternatives throughout the floodplain.

Any process that will impact the severity of the event as defined by timing, depth, velocity, or depth times velocity, will impact the evaluated life loss. Additionally, many non-structural measures, relocation of structures, changes to stronger construction practices, early evacuation warnings, better warning messages and systems, will impact the population remaining, and reduce life loss.

Reductions to life loss or direct economic losses will in turn reduce the factors input into the indirect economic losses.

\section{Indirect economics methodology}

The next step is to summarize the direct losses into factors that feed a methodology to calculate indirect economic losses. To evaluate indirect economic impacts HEC-FIA links to a variant of the (Economics Consequence Assessment Model) ECAM which is a computable general equilibrium model with separate datasets for each county in the United States. Although this model is specifically set up for data in the United States, the requirement for data outside of the United States can be addressed as well. This section describes the basic concepts underlying the ECAM modeling framework. Some further references are available for the interested reader. While direct economic impact estimation is tied directly to the hydraulic event, the approach described below for indirect economic impacts is tied to the reduction in labor and capital rather than the hydraulic event itself. This is why DHS describes the impacts resulting from reductions in labor and capital as indirect damages. As discussed above, the reductions in labor and capital are a function of the hydraulic event, and represent a condition that is predicated on the nature of the event and how it changes due to alternatives and future conditions. Due to this intrinsic connection the indirect economic losses should reflect changes in the floodplain, both structural and non-structural.

The indirect economic ramifications are determined mainly by the population living in the area, and by the severity of the direct economic impact. In order to estimate the complete economic impact of flooding in a logical and consistent manner across multiple counties, numerous potential direct impact characteristics are usually boiled down into a few major parameters, which are then inserted into the economic model. Therefore, it typically does not matter whether the flood is a wall of water that destroys everything downstream, or is simply a rising tide, that eventually inundates several buildings, the resulting effect from an indirect economic standpoint is a loss of workers, buildings, and infrastructure that are necessary inputs used to produce goods and services, which are direct outputs from the direct economic calculation.

As stated in the previous section, the nature of the event may impact the magnitude of the losses, but the same parameters will be input into the indirect model, a loss to available labor, and a loss to available capital.

The approach to indirect impact experiments in ECAM is often called a "counterfactual experiment", which begins with a recent picture of the study area in focus (the factual). The counterfactual is what the economy would have been if the state of the world were changed based on some hazard or shock. The changes considered in the experiments at hand are reductions to physical (productive) capital and reductions to available labor. This provides a before and after picture of the economy. The changes are usually depicted using a percentage change, which are then converted to a total dollar amount.

\subsection{Modeling Framework}

The economy of each region is represented using a Computable General Equilibrium (CGE) model. General equilibrium models have been a mainstay in economic thinking since the early 1950 's, when Arrow and Debreu proved that market equilibrium will exist in most circumstances. Computable general equilibrium models are relatively new, compared to the theory. These models were popularized only after computers became affordable and powerful enough to solve multiple non-linear equations. The early years began in 1982, with work by Shoven and Whalley (1982), but quickly progressed, along with computing power, to present day. CGE models are now a standard tool in the field, with applications across most subdisciplines of economics.

The key advantage of these models is that they utilize optimization as the response to external economic shocks. These models use the base-year dataset to create a snapshot of the production structure for firms and the consumption preferences for households for a particular economy. For the purposes of this study, the "economy" is defined at the county level.

Using the initial dataset, the economy (represented as a county) is assumed to be in "equilibrium". Once the production and consumption functions have been defined, an external shock can be imposed, such as a reduction in available manpower. Each set of firms will respond to this shock differently - labor intensive sectors will scramble to replace the needed workers, who are now in scarce supply. The result for these firms is higher costs and reduced supply. Conversely, other sectors that use more capital than labor will enjoy a comparative advantage, and although they may also decline, the losses won't be as severe as in the labor- 
intensive sectors. Consumers - both private and commercial - will face higher prices, especially for the labor-intensive products. They will re-allocate consumption in order to minimize the inconvenience. This change in the consumption behavior can be done by shifting to substitute goods, or by simply consuming less overall. All of these changes occur more or less simultaneously, and the net impact of each component adds up to the total indirect economic impact of an external shock.

This sort of impact analysis is called "comparative statics", where the benchmark dataset represents the initial state of the world (before the flood), and the production, employment, and consumption values generated by the model after the loss of labor and capital, represent the "counterfactual". The difference between the initial benchmark and the counterfactual are the results. It is essentially a comparison of two separate and "static" situations, which yields the term "comparative statics".

\subsection{Alternative Indirect Economic Modeling Methods}

To be clear, other well-known alternative indirect economic methods are called "input-output" (IO) modeling, and Keynesian-econometric modeling. Each method has strengths and weaknesses. IO models have the advantage of theoretical simplicity, making them easy to deploy - even if they are slightly theoretically unsatisfying. The HAZUS tool (FEMA software) contains an IO module. Keynsian models are more "macro" in nature, and are more suitable for fiscal and monetary policy at the national level rather than regional study area analysis. The methods being utilized in this paper are CGE modeling.

\subsection{Capital Losses}

Capital losses include damage to non-residential buildings and functional structures. Other types of capital losses are items such as roads, bridges, or industrial and computerized equipment. Capital losses make it more difficult (but not impossible) to produce outputs as before.

\subsection{Labor Losses}

Labor losses occur when families are displaced from the impact area, so workers are unable to report for work as under typical circumstances. Like capital losses, fewer workers will reduce the quantity and efficiency of production.

These losses constitute the "external shock" scenario, and the CGE model computes the change in regional output and employment. The next sub-section explains how the input changes are calculated through HECFIA's direct damage estimates for conversion into inputs for ECAM to calculate the indirect economic impacts.
To calculate the losses to a study area's annual production, the estimates and direct damages in HECFIA (described in Section 3) are utilized to evaluate the losses of capital and labor as a percentage of the overall available capital and labor by sector.

To compute labor losses within the HEC-FIA framework, all structures within the inventory that are impacted by an event will be utilized. This means that both residential structures and industrial structures will be utilized in calculating labor loss using the population at 2 p.m. under the age of sixty-five for the population impacted. The justification for that assumption is that although the entire population is not part of the workforce, it is assumed that the ratio of laborers to non-laborers within the floodplain is fixed geospatially and temporally.

To evaluate the labor loss the first step is to identify the number of people impacted by structure at 2 p.m., HEC-FIA outputs this directly. Secondly, the duration of the impact at each structure is calculated. This calculation is comprised of three parts, duration the structure is wet, cleanup time, and the reconstruction time. All time is computed in hours, and added by structure, the number of hours is then multiplied by the impacted population to calculate the hours displaced for the working population. The hours displaced estimate then is converted into labor hours to describe the reduction in availability of labor at that structure for an average worker-year. An assumption of 2,000 working hours per laborer per year is made in the conversion process. Loss of life is translated into a worker year lost. The resulting formula is $\left(D_{s}+C_{s}+R_{s}\right.$ must be limited to one year):

$\mathrm{LL}_{\mathrm{s}}=\left(\mathrm{D}_{\mathrm{s}}+\mathrm{C}_{\mathrm{s}}+\mathrm{R}_{\mathrm{s}}\right) *\left(\frac{2000}{365.25 * 24}\right) *\left(\mathrm{P}_{\mathrm{s}}-\mathrm{L}_{\mathrm{s}}\right)+\mathrm{L}_{\mathrm{s}} * 2000$

Where:
$\mathrm{s}=$ structure
$\mathrm{LL}_{\mathrm{s}}=$ total labor loss at structure in hours
$\mathrm{D}_{\mathrm{s}}=$ duration in hours of flooding at structure
$\mathrm{C}_{\mathrm{s}}=$ cleanup time in hours at structure
$\mathrm{R}_{\mathrm{s}}=$ reconstruction time in hours at structure
$\mathrm{P}_{\mathrm{s}}=$ total population in structure (population during the day under 65 plus population during the day over 65)
$\mathrm{L}_{\mathrm{s}}=$ population that lost their life in structure

Each individual structure labor loss value (Equation 1) represents the number of people that have been removed from the labor force in terms of man hours. To calculate the cumulative labor loss per county (Equation 2) the reduction in labor force hours should be enumerated by county. The formula in general terms is as follows:

$L_{c}=\sum_{i}^{n} L_{s}$ 
Where:

$$
\begin{aligned}
& \mathrm{c}=\text { specified county } \\
& \mathrm{s}=\text { structure } \\
& \mathrm{LL}_{\mathrm{c}}=\text { the labor loss in county } \\
& \mathrm{LL}_{\mathrm{s}}=\text { the labor loss in structure } \\
& \mathrm{n}=\text { total count of structures within county }
\end{aligned}
$$

Each county will also require a calculated total labor supply. This value will be the representation of total available workforce within the county. The labor supply should represent the people within the workforce. A good source of data for available workforce would be the U. S. Bureau of Labor Statistics; another potential resource is the Longitudinal Economic Household Dynamic dataset produced by the U.S. Census. Within HEC-FIA, population over the age of 65 and under the age of 65 at each structure during the day is tracked. To maintain consistency between the calculated numerator and the denominator, it is useful to calculate the denominator by estimating the population during the day in the county, and multiplying that by the fraction of people under the age of 65 . This is a representative number for the "Workforce" (WF).

$$
\begin{aligned}
& \mathrm{WF}_{\mathrm{c}}=\sum_{\mathrm{i}}^{\mathrm{n}} \text { Popday }_{\mathrm{i}} * \text { EldersFrac }_{\mathrm{i}} \\
& \mathrm{LL}_{\mathrm{r}}=\frac{\mathrm{LL}_{\mathrm{c}}}{2000 * \mathrm{WF}_{\mathrm{c}}}
\end{aligned}
$$

\subsection{Calculating Capital Loss Ratios}

Like the labor loss ratios, this process essentially breaks down to three steps. First, calculate the total exposed value by county and store that value. Secondly, calculate the losses by county from the event and store that value. Lastly, divide the losses per county by the total exposed value per county and that is the capital loss ratio by county. To calculate this value, HEC-FIA is accumulating the lost capital in all structures except those that are identified as residential.

The Total Capital $\mathrm{TC}_{\mathrm{c}}$ per county (Equation 5) is the summation of all nonresidential structure and content value within a county.

$\mathrm{TC}_{\mathrm{c}}=\mathrm{TIC}_{\mathrm{c}}+\mathrm{TCC}_{\mathrm{c}}+\mathrm{TPC}_{\mathrm{c}}$

Where:

$$
\begin{aligned}
& \mathrm{c}=\text { county } \\
& \mathrm{TIC}_{\mathrm{c}}=\text { total industrial Capital for the county } \\
& \mathrm{TCC}_{\mathrm{c}}=\text { total commercial Capital for the county } \\
& \mathrm{TPC}_{\mathrm{c}}=\text { total public Capital for the county }
\end{aligned}
$$

As an event is simulated, the total damaged capital by impact area will be calculated to represent the Lost Capital (Equation 6) by category by county.

$$
\mathrm{LC}_{\mathrm{c}}=\mathrm{LIC}_{\mathrm{c}}+\mathrm{LCC}_{\mathrm{c}}+\mathrm{LPC}_{\mathrm{c}}
$$

Where:

$$
\begin{aligned}
& \mathrm{c}=\text { country } \\
& \mathrm{LIC}_{\mathrm{c}}=\text { total lost industrial Capital for the county } \\
& \mathrm{LCC}_{\mathrm{c}}=\text { total lost commercial Capital for the } \\
& \mathrm{LPC}_{\mathrm{c}}=\text { total lost public Capital for the county }
\end{aligned}
$$
county

Once these values have been calculated the ratio will be constructed so that the Capital Loss Ratio (Equation 7) is the lost capital divided by the total capital by county. This value results in the Capital Loss ratio, or reduction in functioning capital within an economy.

$$
\mathrm{CL}_{\mathrm{r}}=\frac{\mathrm{LC}_{\mathrm{c}}}{\mathrm{TC}_{\mathrm{c}}}
$$

\subsection{Economic Multipliers for the CGE Model}

To convert the loss ratios into a reduction in economic output, a CGE model needs to know about the specific nature of the economy being analyzed. The primary need for a CGE model like ECAM, is to determine if the economy in question is capital or labor intensive, and what the rate of exchange is between labor and capital. Each county in the United States has a unique dataset to define the specific economic characteristics in question. The software and datasets were created by the Minnesota IMPLAN Group (MIG, Inc.). IMPLAN (IMpact analysis for PLANning) is the only data source available with a sufficient level of detail, internally consistent accounts, and broad availability to meet the demands of this calculation. The ECAM system model uses county-level data so that any county or group of counties in the United States can be analyzed. Statistics for production, employment, income and all other economic indicators are based upon the IMPLAN dataset, unless otherwise indicated. In some cases, the IMPLAN data is less precise than other sources of data, such as some geographic data available in the HAZUS tool. In these cases, the IMPLAN data can be augmented or adjusted.

Each of these datasets can distinguish up to 440 separate production activities, ten household types, and four levels of government. The dataset used for evaluating indirect economics with ECAM and HECFIA has been aggregated from the full 440 sectors to thirty sectors. This is the standard level of aggregation that is used in indirect modeling. Table 1 provides a description for each sector in the thirty-sector datasets used within HEC-FIA and ECAM. 
Table 1. Description of Sectors*

\begin{tabular}{|c|c|c|c|}
\hline Code & Description & Code & Description \\
\hline AGR & Agriculture & CHM & $\begin{array}{l}\text { Chemical } \\
\text { processing \& } \\
\text { refining }\end{array}$ \\
\hline LVS & $\begin{array}{l}\text { Livestock \& } \\
\text { ranching }\end{array}$ & MAN & Manufacturing \\
\hline FRS & Forestry & ELE & Instruments \\
\hline FSH & Fishing & CAR & $\begin{array}{l}\text { Transportation } \\
\text { equipment } \\
\text { manufacturing }\end{array}$ \\
\hline CRU & $\begin{array}{l}\text { Oil, gas, and } \\
\text { coal extraction }\end{array}$ & FRN & $\begin{array}{l}\text { Furniture } \\
\text { manufacturing }\end{array}$ \\
\hline MIN & $\begin{array}{l}\text { Minerals } \\
\text { mining }\end{array}$ & $\mathrm{COM}$ & $\begin{array}{l}\text { Post \& } \\
\text { communication } \\
\text { s }\end{array}$ \\
\hline PWR & $\begin{array}{l}\text { Electric power } \\
\text { generation \& } \\
\text { supply }\end{array}$ & TRN & $\begin{array}{l}\text { Transportation } \\
\text { services }\end{array}$ \\
\hline GAS & $\begin{array}{l}\text { Natural gas } \\
\text { distribution }\end{array}$ & TRD & $\begin{array}{ll}\text { Wholesale } & \& \\
\text { retail } & \\
\text { distribution } & \\
\text { services } & \end{array}$ \\
\hline WTR & $\begin{array}{l}\text { Water, } \\
\text { sewage, \& \& } \\
\text { other systems }\end{array}$ & INF & $\begin{array}{l}\text { Information } \\
\text { processing } \quad \& \\
\text { publication }\end{array}$ \\
\hline $\mathrm{CON}$ & Construction & FIN & $\begin{array}{l}\text { Financial } \\
\text { services } \quad \& \\
\text { insurance }\end{array}$ \\
\hline FOD & $\begin{array}{l}\text { Food } \\
\text { processing }\end{array}$ & RES & $\begin{array}{l}\text { Recreation } \\
\text { activities }\end{array}$ \\
\hline $\mathrm{BEV}$ & Beverages & SER & $\begin{array}{ll}\text { All } & \text { other } \\
\text { services } & \\
\end{array}$ \\
\hline TBC & Tobacco & ORG & Households \\
\hline TEX & $\begin{array}{ll}\text { Textiles } \quad \& \\
\text { wearing } \\
\text { apparel }\end{array}$ & GOV & $\begin{array}{l}\text { State \& federal } \\
\text { government }\end{array}$ \\
\hline WOD & $\begin{array}{l}\text { Wood } \\
\text { manufacturing }\end{array}$ & RWJ & 507 \\
\hline PPP & $\begin{array}{l}\text { Paper, } \\
\text { printing, \& } \\
\text { publishing }\end{array}$ & IVJ & $\begin{array}{l}\text { Inventory } \\
\text { Valuation } \\
\text { Adjustment } \\
(508)\end{array}$ \\
\hline DWE & $\begin{array}{l}\text { Owner } \\
\text { occupied } \\
\text { dwellings } \\
(509)\end{array}$ & & \\
\hline
\end{tabular}

*Thirty industries are described. Notice that they do not user numbers, but instead, they use a three-letter code.

Notice that about half of the sectors are production based, and that half are service based. A common mistake for non-economists is to have so-called "production bias". This "bias" is a pre-conception that all economic activity is based upon industrial production. In reality, most of the economic activity lies in the services sector, and industrial output is relatively small. Services represent 72 percent of the United States GDP (gross domestic product) on average, and services are typically an even larger share of GDP for small counties. These services are primarily financial services, telecommunications, transportation, information, recreation, and government. Rural counties also tend to have more agriculture output, rather than industrial output as a share of regional GDP. The aggregation used here takes these factors into account and provides sufficient detail in the services sectors to understand how the economy may be impacted.

\section{Model Limitations}

The methodologies utilized in this paper are complex and extremely sensitive. Calculating direct economic damages from flooding is rapt with uncertainty, evaluating population impacts is equally uncertain, and finally combining those losses into a computable general equilibrium model magnifies the uncertainty considerably. Using CGE modeling to assess indirect impacts of flood events should be limited to large scale losses. For smaller scale losses $\mathrm{I} / \mathrm{O}$ modeling is typically a more dependable methodology.

\section{Conclusion}

The intent of this paper is to outline methodologies to incorporate additional consequence calculations into the evaluation of project alternatives within areas impacted by natural hazards. The reason is based on the need to adequately look at the future condition and how the transformation of risk is a function of both the change of human behavior and of the change in the hazard itself. By evaluating the impact to the economy based on duration of time when production cannot occur and the dependency of the economy on the areas impacted by the hazard, HEC-FIA allows users to evaluate how resilient their human intervention strategies are in the inevitable future failure or degradation of structural measures. The hope is that the recognition of this connection may be able to establish how our practices impact the resiliency of a project across time. It may become evident that nonstructural measures like raised infrastructure, natural floodways, and planned development strategies may be able to create more resilient human intervention alternatives for the long term. Although the cost may be greater, the justification of that cost may also be able to acknowledge the impact of age and human behavior on the ability of the structural measures alone to provide adequate protection from natural hazards. 


\section{References}

Fields, Bahner, Needham, and Goodell, 2012: "Dam and Levee Safety Risk Assessment - Evaluation

Routing and Life Loss Estimation using LIFESim". United States Society on Dams (USSD), Conference on Innovative Dam and Levee Design and Construction for Sustainable Water Management, New Orleans, LA; 23-27 April 2012.

USACE, 2000. Planning Guidance Notebook, ER 1105-2-100. USACE, Washington D.C.

Jonkman, S.N., 2007: "Loss of Life Estimation in Flood Risk Assessment - Theory and Applications",

Dissertation, Delft University of Technology, Civil Engineering and Geosciences, The Netherlands; 354 pages.

EGM, 2003. Generic Depth-Damage Relationships, Economic Guidance Memorandum (EGM) 01-03.

Shoven, J., Whalley, J., and Goulder, L.H. 1982: "Domestic Tax Policy and the Foreign Sector: The Importance of Alternative Foreign Sector Formulations to Results from a General Equilibrium Tax Analysis Model". Working Paper No. 919, National Bureau of Economic Research, University of Chicago Press, Chicago, IL, pp. 333-368.

Arrow and Debreu, 1954: "Existence of an Equilibrium for a Competitive Economy". ECONOMETRICA, Volume 22, Number 3, The Econometirc Society, pp 265-290

Aboelata and Bowles, 2005: "LIFESim: A Model for Estimating Dam Failure Life Loss". Report to Institute for Water Resources, U.S. Army Corps of Engineers and Australian National Committee on Large Dams by Institute for Dam Safety Risk Management, Utah State University, Logan, Utah.

USACE, 2010. Risk Analysis for Flood Damage Reduction Studies, ER 1105-2-101, Draft, USACE, Washington D.C.

USACE, 2010a. Risk-Based Analysis for Flood Damage Reduction Studies, EM 1110-2-1619, Draft, USACE, Washington D.C.

Needham, J. T., 2010: "Estimating Loss of Life from Dam Failure with HEC-FIA", U.S. Army Corps of Engineers, Risk Management Center, U.S. Army Corps of Engineers, Davis, CA 95616

Rogers, G. O. and J. H. Sorensen, 1991: "Diffusion of Emergency Warning: Comparing Empirical and Simulation Results." Risk Analysis Prospects and Opportunities, C. Zerros et al. (eds.), Plenum Press, New York, p. 117 - 134.

U.S. Department of Homeland Security, Federal Emergency Management Agency, 2007: "MultiHazard Loss Estimation Methodology Flood Model HAZUS-MH MR3 Technical Manual", Washington, D. C.

McClelland, D.M. and D.S. Bowles, 2002: Estimating Life Loss for Dam Safety Risk Assessment - a Review and New Approach, U.S. Army Corps of Engineers, Institute for Water Resources, Alexandria, VA. 